\title{
Increased vulnerability of Zostera noltii to stress caused by low light and elevated ammonium levels under phosphate deficiency
}

\author{
Fernando G. Brun ${ }^{1,3, *}$, Irene Olivé ${ }^{1}$, Erik-jan Malta ${ }^{2}$, Juan J. Vergara1, \\ Ignacio Hernández ${ }^{1}$, J. Lucas Pérez-Lloréns ${ }^{1}$ \\ ${ }^{1}$ Departamento de Biología, Area de Ecología, Facultad de Ciencias del Mar y Ambientales, Universidad de Cádiz, \\ 11510 Puerto Real, Cádiz, Spain \\ ${ }^{2}$ ALGAE - Marine Plant Ecology Research Group, CCMAR, Universidade do Algarve, Gambelas, 8005-139 Faro, Portugal \\ ${ }^{3}$ Present address: Netherlands Institute of Ecology (NIOO-KNAW), Centre for Estuarine and Marine Ecology, \\ Korringaweg 7, 4401 NT Yerseke, The Netherlands
}

\begin{abstract}
The effects of light and ammonium levels on net production, fluorescence parameters and non-structural carbohydrates of the seagrass Zostera noltii under different phosphate conditions were studied. A fully factorial design was used with light (low/high levels), ammonium supply and phosphate preculture conditions of the plants as the experimental variables. Both ammonium supply and low light caused negative and synergistic effects on net production, while ammonium toxicity was more severe at high light levels; in this case, it was independent of the non-structural carbohydrate (sucrose and starch) content. Preculturing of plant with added phosphate alleviated the ammonium toxicity, and also attenuated the negative production balance of plants grown at low light levels. The results indicated that phosphate preculture ameliorated the plant's short-term response against the assayed stressors (low light, high ammonium) significantly. An overall consumption of non-structural carbohydrates in response to environmental stressors was recorded throughout the experiment, indicating the importance of carbon and phosphorus reserves to cope with adverse conditions. In addition, phosphate deficiency increased the vulnerability of plants, which could have negative ecological consequences for seagrass species thriving under phosphate deficiency conditions, or in developing seagrass transplantation programs.
\end{abstract}

KEY WORDS: Ammonium toxicity $\cdot$ Carbohydrates $\cdot$ Eutrophication $\cdot$ Fluorescence $\cdot$ Net production $\cdot$ Phosphate limitation · Seagrass

Resale or republication not permitted without written consent of the publisher

\section{INTRODUCTION}

Human-driven seagrass declines have been frequently reported (Short \& Wyllie-Echevarria 1996, Ralph et al. 2006) and have been shown to profoundly affect ecosystem functioning and its associated socioeconomical functions (Ralph et al. 2006). Mostly, these declines are prompted (directly or indirectly) by 2 processes that are often (but not necessarily) interrelated: (1) a reduction in the underwater light climate and (2) an increase in nutrient loads. The effect of the first process is easily explained. Higher water column turbidity leads to a lower light availability for seagrass photo- synthesis, directly affecting plant growth and performance, as has been demonstrated for Zostera noltii (Peralta et al. 2002, Brun et al. 2003b,c, Olivé et al. 2007) and other seagrass species (Longstaff et al. 1999, Ruíz \& Romero 2001).

The effect of increasing nutrient discharges on coastal waters from land wastewater or agricultural runoff is less straightforward. Apart from reducing underwater irradiance by enhancing phytoplankton and ephemeral macroalgal growth (Hernández et al. 1997, Valiela et al. 1997), it can also have a direct negative effect on seagrass populations. Direct toxicity of certain forms of nitrogen (nitrate and ammonium) on 
seagrasses has been demonstrated (Burkholder et al. 1992, 1994 for nitrate; van Katwijk et al. 1997 and Brun et al. 2002 for ammonium) at concentrations as low as $16 \mu \mathrm{m}$ ammonium. Seagrass leaves take up ammonium in direct proportion to the concentration in the surrounding water, but are not capable of controlling it (Thursby \& Harlin 1982, Iizumi \& Hattory 1982, van Katwijk et al. 1997, Touchette \& Burkholder 2000). Intracellular ammonium has to be rapidly assimilated into organic compounds to prevent its accumulation to potentially harmful levels, as was shown in an experiment with the seagrass Posidonia oceanica, which maintained low intracellular ammonium levels regardless of the nitrogen enrichment levels at which plants were grown (Invers et al. 2004).

Ammonium toxicity mechanisms are complex and not fully understood (Britto \& Kronzucher 2002), but the physiological mechanisms are thought to be a combination (among others) of: (1) the uncoupling of ATP production during the photosynthetic electron transport that is triggered by ammonia (Goyal et al. 1982, Marschner 1995), (2) the intracellular depletion of essential cations (such as potassium and magnesium; Kirkby 1968, van Katwijk et al. 1997) that is accompanied by the increase of intracellular inorganic anions (e.g. phosphate; Cruz et al. 1993, van Katwijk et al. 1997), (3) an increase of the demand on carbon skeletons and respiration (Brun et al. 2002, Invers et al. 2004) and (4) the high energetic cost of pumping out intracellular ammonium (Britto et al. 2001). Since 3 of the 4 aforementioned mechanisms are related to the energy budget (ATP production and/or consumption) and the carbon skeleton, both of which are tied to photosynthesis, the photosynthesis rate and the pool of carbon reserves may play a key role in determining potential toxic effects of ammonium in plants. While the availability of carbohydrate reserves (mainly in the form of sucrose and starch) was previously shown to be crucial in shifting ammonium from being a nutrient to a toxin in the seagrass Zostera noltii (Brun et al. 2002), the effect of light levels has not been investigated so far.

In this context, it is clear that it is not always a single factor, but often a combination of factors that better explain episodical die-off in seagrasses. To improve our knowledge of the mechanisms behind ammonium toxicity, we developed an experimental set-up in which 2 main stressors (low light and elevated ammonium load), frequently co-occurring in coastal waters, were assayed together in a factorial design. Furthermore, considering some of the mechanisms mentioned above for ammonium toxicity (e.g. tissue ionic unbalance with an increase of intracellular phosphate), and together with previous findings on the involvement of phosphate as a modulator of the ammonium toxicity
(Brun et al. 2002), phosphate condition was used as an additional factor in the experiments. In the present study, phosphate and ammonium were not supplied simultaneously as in Brun et al. (2002), but the effect of contrasting phosphorous (P) quotas (achieved by preculturing plants under high and low phosphate levels over 2 wk) on ammonium toxicity was investigated.

\section{MATERIALS AND METHODS}

Sampling site and plant collection. Specimens of the seagrass Zostera noltii Horneman were collected from intertidal mudflats in Los Toruños, a salt marsh ecosystem of 773 ha situated in the Cadiz Bay Natural Park $\left(36^{\circ} 30^{\prime} \mathrm{N}, 6^{\circ} 10^{\prime} \mathrm{W}\right)$. At this location, water nutrient concentrations show a seasonal fluctuation, with the highest values in winter (up to $12 \mu \mathrm{m}$ nitrate, $25 \mu \mathrm{m}$ ammonium and $1.5 \mu \mathrm{m}$ phosphate; see Brun et al. 2003b for further information). Porewater nutrient concentrations within seagrass beds ranged from 10 to $225 \mu \mathrm{m}$ ammonium and 2 to $23 \mu \mathrm{m}$ phosphate (F. G. Brun unpubl. data). Plants of $Z$. noltii were collected carefully to keep belowground structures intact and transported to the laboratory in an icechest within 30 min of collection. Upon arrival, plants were rinsed in seawater and visible epiphytes removed by gently scraping. More than 300 'experimental plant units' (EPUs) were selected for the experiment. An EPU was defined as a single plant with 2 rhizome internodes, the corresponding roots and the apical shoot plus the first lateral shoot.

Experimental design. EPUs were transplanted into 2 aquaria (100 l), each containing a clean natural sediment layer (5 cm depth) and filled with filtered natural seawater (Whatman GF/C filters). The aquaria were then placed together in an incubation chamber (D-1400-3BL, ASL) under constant temperature $\left(18.5^{\circ} \mathrm{C}\right.$ ) and light conditions (200 to $220 \mu \mathrm{mol}$ photons $\mathrm{m}^{-2} \mathrm{~s}^{-1}$ in a $14 \mathrm{~h}$ light:10 h dark photoperiod) for $1 \mathrm{wk}$ (acclimation period). Samples (triplicate) for water nutrient concentrations were taken during preculture and at the beginning of the experimental period, both from the freshly collected seawater and after nutrient additions to the different treatments. Ammonium was measured following the method of Koroleff (1976), while reactive soluble phosphorus was analysed by using the molybdate blue method (Murphy \& Riley 1962).

Following the acclimation period, all EPUs were collected, the sediment was mixed and cleaned again (for further use), and the EPUs were reallocated into ten, 201 aquaria, where they were incubated for $2 \mathrm{wk}$ under the same conditions mentioned above. During this precultivation phase, the water from 5 aquaria 
was enriched with phosphate (10 to $15 \mu \mathrm{m}$, final concentration; phosphate precultured EPUs), whereas the remaining aquaria were not phosphate-enriched ( $<1 \mu \mathrm{m}$, final concentration; non-precultured EPUs). The measured ammonium concentration was low in all aquaria (1 to $3 \mu \mathrm{m}$ natural seawater concentration). Seawater was renewed every 5 d (i.e. Days 5, 10 and 15), aquaria were reallocated haphazardly under the same light treatment in the climatic chamber, and 2 EPUs from each aquarium (10 EPUs in total) were haphazardly selected for plant analysis at these sampling dates.

At the end of the precultivation phase, all EPUs were weighed and tagged individually (above- and belowground tissues together). When necessary (i.e. for newly grown lateral shoots or internodes), the surplus plant material was excised to get the 'standard' EPUs, as described above. New natural sediment was washed and mixed to fill 8 aquaria (sediment height $5 \mathrm{~cm}$ ) for the experimental phase. Thirty EPUs were transplanted into each aquarium, with 15 coming from phosphate-enriched and the remaining 15 from phosphate-depleted precultivation phases. A factorial experiment was designed with ammonium, light and phosphate preculture condition as stress factors. This resulted in 8 different treatments: 4 for high light (with and without ammonium enrichment in EPUs and precultivated with or without added phosphate; i.e. HL + $\mathrm{N}+\mathrm{P}, \mathrm{HL}+\mathrm{N}-\mathrm{P}, \mathrm{HL}-\mathrm{N}+\mathrm{P}$ and $\mathrm{HL}-\mathrm{N}-\mathrm{P}$, respectively), and 4 for low light (LL $+\mathrm{N}+\mathrm{P}, \mathrm{LL}+\mathrm{N}-\mathrm{P}, \mathrm{LL}-$ $\mathrm{N}+\mathrm{P}$ and $\mathrm{LL}-\mathrm{N}-\mathrm{P}$ ). Two aquaria were incubated for each combination of ammonium and light treatment. Daily ammonium doses (10 to $15 \mu \mathrm{m}$ final concentration in water) were chosen according to Brun et al. (2002), and light levels according to Peralta et al. (2002) and Brun et al. (2003a). Saturating light intensity was set at $220 \mu \mathrm{mol}$ photons $\mathrm{m}^{-2} \mathrm{~s}^{-1}$ (12 mol photons $\mathrm{m}^{-2} \mathrm{~d}^{-1}$ ) and limiting light at $25 \mu \mathrm{mol}$ photons $\mathrm{m}^{-2}$ $\mathrm{s}^{-1}$ (1.5 mol photons $\left.\mathrm{m}^{-2} \mathrm{~d}^{-1}\right)$. Light was provided by fluorescent tubes (Philips TL20W/54RS) and measured with a LI 193 SA (LiCor) quantum meter mounted with a $4 \pi$ PAR (400 to $700 \mathrm{~nm}$ ) sensor. The photoperiod was kept at $14 \mathrm{~h}$ light:10 $\mathrm{h}$ dark, and the temperature at $18.5^{\circ} \mathrm{C}$. All aquaria were placed together in the same incubation chamber.

Water was renewed every $5 \mathrm{~d}$ with freshly collected, filtered natural seawater (Whatman GF/C filters). From each aquarium, 6 EPUs (3 preincubated with $\mathrm{P}$ and 3 without $\mathrm{P}$ ) were haphazardly harvested for plant analysis (see below) at 1, 4, 8, 14 and $21 \mathrm{~d}$ after plant transplantation. Time 0 was set for the day following plant transplantation.

Plant analysis. EPUs harvested at each time interval were carefully cleaned, blotted dry with tissue, and weighed. Differences in plant weight between the onset of the experiment (time 0) and collection time were used to calculate the net production; that is, the weight gain (or loss) per time unit of the whole plant. As the whole plant was weighed (including both above- and belowground tissues) and apical shoots were used as EPUs, the weight gain mainly reflects the production of new horizontal rhizomes and the appearance (recruitment) of new shoots. In contrast, negative net production values mainly indicate that leaf (and/or shoot) losses exceed the recruitment of new leaves and/or a minor horizontal rhizome elongation. Net production was expressed as milligrams of fresh weight per plant per day. After weighing, each EPU was split into above- and belowground parts, dried until constant weight $\left(60^{\circ} \mathrm{C}\right)$ and used for determinations of tissue phosphorus and non-soluble carbohydrate (NSC) contents. Main NSCs (sucrose and starch) were analysed according to Hubber \& Israel (1982). Tissue phosphorus concentration was quantified by the persulphate digestion method (APHA 1992).

Fluorescence measurements. Photosynthetic performance was assessed by measuring the effective and maximum quantum yield of photosynthesis through measurements of chl a fluorescence using a PAM-2000 (Walz) (for details on this technique see Krause \& Weis 1991). Measurements were carried out at the beginning of the experiment, at the end of the precultivation phase, and throughout the experimental period on the plants later used for plant analysis. Measurements during the experimental period were performed on 6 EPUs per aquarium (3 preincubated with $P$ and 3 without P) at every successive sampling event. Dark leaf clips (Diving-LC, Walz) were mounted on the base of the second innermost leaf of each EPU. A 5 s, weak, far-red pulse was administered to oxidise the electron transport chain, after which the shutters were closed. After 10 min of dark acclimatisation (long enough to achieve the highest values of $F_{\mathrm{v}} / F_{\mathrm{m}}$ as previously determined), $F_{0}$ and $F_{\mathrm{m}}$ (ground and maximum fluorescence, respectively) were measured, and variable fluorescence $\left(F_{\mathrm{v}}=F_{\mathrm{m}}-F_{0}\right)$ and maximum quantum yield of Photosystem II (PSII $F_{\mathrm{v}} / F_{\mathrm{m}}$ ) were calculated. Following this, relative electron transport rates (rETR) versus irradiance curves were determined as rapid light curves (RLCs; e.g. Bischof et al. 2000). The EPUs were subjected to a series of 10 increasing PAR intensities, ranging from 44 to $2004 \mu \mathrm{mol}$ photons $\mathrm{m}^{-2} \mathrm{~s}^{-1}$ for $30 \mathrm{~s}$ at each intensity, using the halogen lamp from the PAM as a light source. Subsequently, $F_{\mathrm{t}}$ and $F_{\mathrm{m}}$ ' were measured and $F / F_{\mathrm{m}}{ }^{\prime}$ was calculated. rETR was computed as $F / F_{\mathrm{m}}{ }^{\prime} \times \mathrm{PAR} \times 0.5$ (assuming that both photosystems absorbed an equal amount of light). The rETR was fitted to PAR according to the model of Platt et al. (1980). In this way, estimates for the rETR/I curve parameters (initial slope, $\alpha$ ) were obtained and maximum relative 
ETR $\left(\mathrm{rETR}_{\mathrm{m}}\right)$, and optimal light intensity $\left(I_{\mathrm{opt}}\right)$ were deduced from these calculations.

Statistics. The main effects of phosphate preculture, ammonium supply and light levels on net production, non-structural carbohydrates, phosphorus content and fluorescence parameters were tested using a multifactorial ANOVA with aquaria as experimental units. Furthermore, the interactions between phosphate-preculture, ammonium supply and light levels were tested in the following way: (phosphate-preculture) $\times$ (ammonium supply), (phosphate-preculture) $\times$ (light levels) and (ammonium supply) $\times$ (light levels) Space restrictions within the incubation chamber and the complex experimental design reduced the number of real independent replicates ( 2 independent aquaria) for each sampling event (pseudo-replication within each aquarium is achieved at every sampling time). However, the sources of potential variability between aquaria were controlled (same incubation chamber, aquaria were moved within the chamber, same sediment and water pool, water was renewed frequently, etc.) and we used a large amount of EPUs, which can be considered as single individuals. Consequently at every sampling event, the measured effects on the plants had to come from the imposed treatments (light, ammonium supply and phosphate preculture). Thus, particular conditions were considered so that, when the whole experimental period has been statistically analysed, each sampling event represents an independent replicate. Normality of the data and homogeneity of variances were tested following Zar (1984). All variables were normally distributed, except the sucrose content (both above- and belowground), which was log-transformed. Multiple post hoc comparisons between means were achieved by the Tukey test procedure (Zar 1984). The level of significance $(\alpha)$ was set at 0.05 probability. Data are shown as means \pm 1 standard error.

\section{RESULTS}

\section{Net production}

Phosphate precultivation had a clear effect on net production. Added phosphate alleviated the negative effects caused both by ammonium enrichment and low light levels (Fig. 1A). This led to a significant increase in average net production at HL, as well as less negative values at LL. In fact, negative net production values were recorded in all EPUs growing at LL, regardless of ammonium addition or precultivation conditions, but the most severe effects were observed in those EPUs precultured without phosphate (Fig. 1A).

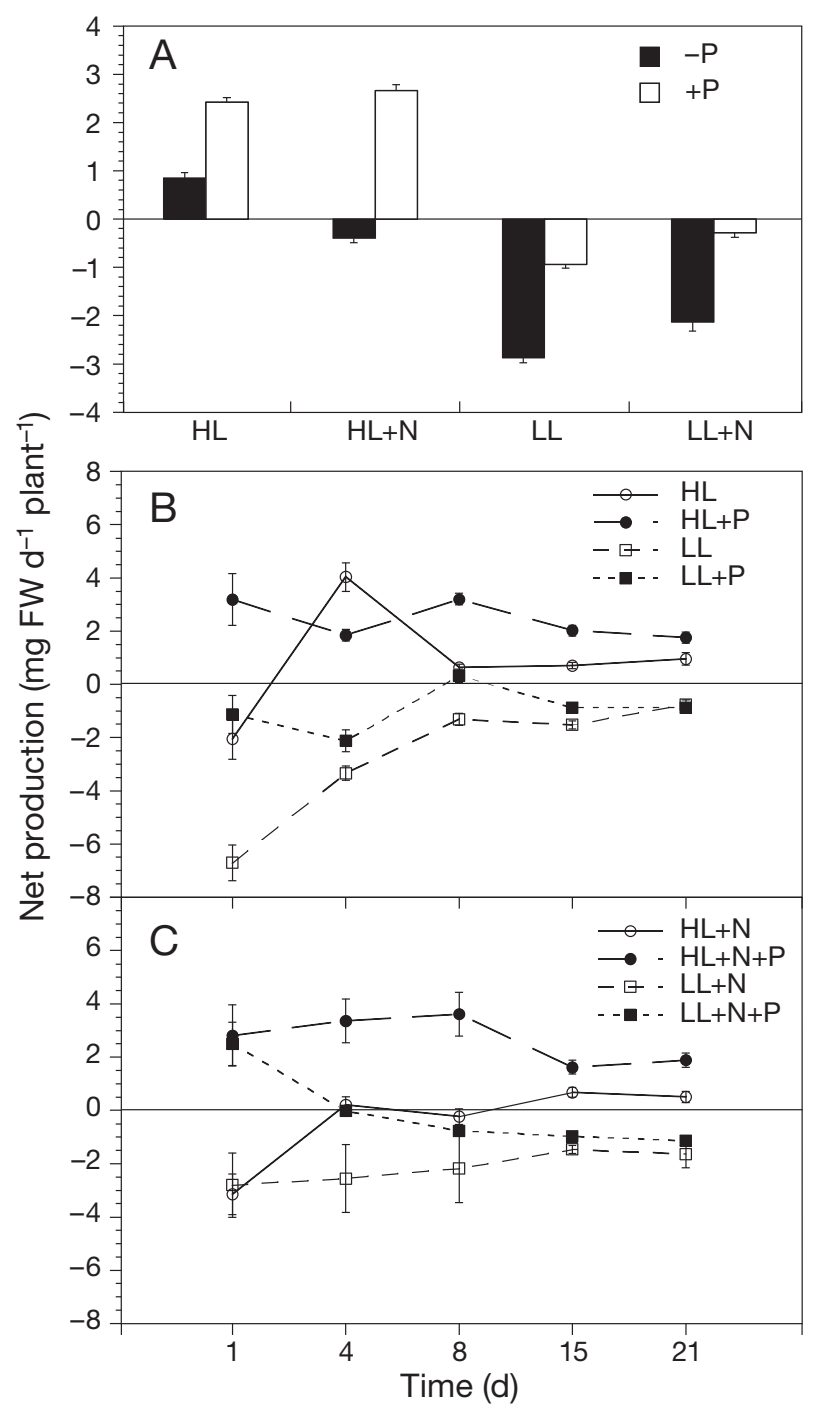

Fig. 1. Zostera noltii. Net production in plants subjected to a factorial experimental design with light (HL: high light; LL: low light), different phosphate precultivation (+P: added phosphate, $-\mathrm{P}$ : no added phosphate) and elevated ammonium supply $(+\mathrm{N})$ as factors. (A) Averaged (whole plant) net production for the entire experiment $(n=30)$. (B) Time course of net production in plants subjected to light and phosphate-precultivation treatments. (C) Time course of net production in plants subjected to light, ammonium supply and phosphate-precultivation treatments. Plants were harvested for analysis at times $1,4,815$ and $21 \mathrm{~d}(\mathrm{n}=6)$. The experiment lasted for $21 \mathrm{~d}$. Data are presented as means $\pm 1 \mathrm{SE}$. FW: fresh weight

The time course analysis of net production (Fig. 1B,C) revealed that: first, there were significant differences at the onset of the experimental phase (Day 1), especially between EPUs grown under different phosphate conditions. EPUs precultured with added phosphate showed the highest net production, whereas EPUs precultured without the addition of phosphate and grown at LL levels showed the lowest values (Fig. 1B,C). Second, the variability of the net 
production rates during the experiment depended mainly on preculture conditions. Thus, the smallest fluctuations (except EPUs grown at LL under ammonium enrichment) were observed in EPUs precultured with added phosphate (Fig. 1B,C). Third, at the end of the experiment (Day 21), net production was significantly affected by light, ammonium and phosphate preculture conditions (Tables $1 \& 2$ ).

\section{Non-structural carbohydrates and tissue phosphorus concentration}

The NSC concentrations at the end of the precultivation phase (Time 0) were unaffected by phosphate. However, there was an overall decrease in sucrose and starch concentrations, mostly in belowground parts of the EPUs ( $60 \%$ in sucrose), from the onset of the experimental period. This could be attributed to the manipulation of the field plants (e.g. handling, cutting and transplantation; Fig. 2). Average sucrose concentrations over the entire experimental period in above-

Table 1. Zostera noltii. Statistical results of the factorial ANOVA analysis, examining the effects of light reduction, N supply, P-precultivation (added phosphate) and collecting time on net production, sucrose content and fluorescence parameters throughout the experiment. Bold: significant

\begin{tabular}{|c|c|c|}
\hline Variables, factors & df treatments/df error & $F(\mathrm{p})$ \\
\hline \multicolumn{3}{|l|}{ Net production } \\
\hline P-preculture (P) & $1 / 216$ & $30.6(<\mathbf{0 . 0 0 0 1})$ \\
\hline N supply (N) & $1 / 216$ & $5.16(\mathbf{0 . 0 2 4})$ \\
\hline Light levels (L) & $1 / 216$ & $58.2(<\mathbf{0 . 0 0 0 1})$ \\
\hline Time & $4 / 216$ & $0.82(0.51)$ \\
\hline $\mathrm{P} \times \mathrm{N}$ & $1 / 216$ & $4.63(\mathbf{0 . 0 3 2})$ \\
\hline $\mathrm{P} \times \mathrm{L}$ & $1 / 216$ & $2.08(0.15)$ \\
\hline $\mathrm{N} \times \mathrm{L}$ & $1 / 216$ & $2.71(0.10)$ \\
\hline \multicolumn{3}{|c|}{ Above-ground sucrose } \\
\hline P-preculture (P) & $1 / 112$ & $1.47(0.23)$ \\
\hline N supply (N) & $1 / 112$ & $22.9(<\mathbf{0 . 0 0 0 1})$ \\
\hline Light levels (L) & $1 / 112$ & $150.3(<\mathbf{0 . 0 0 0 1})$ \\
\hline Time & $4 / 112$ & $4.33(\mathbf{0 . 0 0 3})$ \\
\hline $\mathrm{P} \times \mathrm{N}$ & $1 / 112$ & $2.53(0.12)$ \\
\hline $\mathrm{P} \times \mathrm{L}$ & $1 / 112$ & $0.043(0.84)$ \\
\hline $\mathrm{N} \times \mathrm{L}$ & $1 / 112$ & $0.16(0.69)$ \\
\hline \multicolumn{3}{|c|}{ Below-ground sucrose } \\
\hline P-preculture (P) & $1 / 112$ & $1.1(0.29)$ \\
\hline $\mathrm{N}$ supply $(\mathrm{N})$ & $1 / 112$ & $5.28(\mathbf{0 . 0 2 3})$ \\
\hline Light levels (L) & $1 / 112$ & $105.7(<\mathbf{0 . 0 0 0 1})$ \\
\hline Time & $4 / 112$ & $3.09(\mathbf{0 . 0 1 8})$ \\
\hline $\mathrm{P} \times \mathrm{N}$ & $1 / 112$ & $4.36(\mathbf{0 . 0 4 3})$ \\
\hline $\mathrm{P} \times \mathrm{L}$ & $1 / 112$ & $13.6(\mathbf{0 . 0 0 0 3 6})$ \\
\hline $\mathrm{N} \times \mathrm{L}$ & $1 / 112$ & $0.071(0.79)$ \\
\hline \multicolumn{3}{|l|}{$F_{\mathrm{v}} / F_{\mathrm{m}}$} \\
\hline P-preculture (P) & $1 / 40$ & $5.37(\mathbf{0 . 0 2 2})$ \\
\hline $\mathrm{N}$ supply (N) & $1 / 40$ & $4.67(\mathbf{0 . 0 3 2})$ \\
\hline Light levels (L) & $1 / 40$ & $2.78(0.097)$ \\
\hline Time & $4 / 40$ & $20.69(\mathbf{0 . 0 0 0 8})$ \\
\hline
\end{tabular}

Table 2. Zostera noltii. Statistical results of the factorial ANOVA analysis, examining the effects of light reduction, $\mathrm{N}$ supply and P-precultivation (added phosphate) on net production, sucrose content, phosphorous tissue concentration and fluorescence parameters at the end of the experiment (Day 21). Bold: significant

\begin{tabular}{|c|c|c|}
\hline Variables, factors & df treatments/df error & $F(\mathrm{p})$ \\
\hline \multicolumn{3}{|l|}{ Net production } \\
\hline P-preculture (P) & $1 / 232$ & $26.2(<\mathbf{0 . 0 0 0 1})$ \\
\hline $\mathrm{N}$ supply $(\mathrm{N})$ & $1 / 232$ & $4.41(\mathbf{0 . 0 3 7})$ \\
\hline Light levels (L) & $1 / 232$ & $49.8(<\mathbf{0 . 0 0 0 1})$ \\
\hline $\mathrm{P} \times \mathrm{N}$ & $1 / 232$ & $3.96(0.047)$ \\
\hline $\mathrm{P} \times \mathrm{L}$ & $1 / 232$ & $1.78(0.18)$ \\
\hline $\mathrm{N} \times \mathrm{L}$ & $1 / 232$ & $2.32(0.13)$ \\
\hline \multicolumn{3}{|c|}{ Above-ground sucrose } \\
\hline P-preculture (P) & $1 / 116$ & $1.34(0.25)$ \\
\hline N supply (N) & $1 / 116$ & $21.3(<\mathbf{0 . 0 0 0 1})$ \\
\hline Light levels (L) & $1 / 116$ & $134.6(<\mathbf{0 . 0 0 0 1})$ \\
\hline $\mathrm{P} \times \mathrm{N}$ & $1 / 116$ & $2.23(0.14)$ \\
\hline $\mathrm{P} \times \mathrm{L}$ & $1 / 116$ & $0.02(0.88)$ \\
\hline $\mathrm{N} \times \mathrm{L}$ & $1 / 116$ & $0.15(0.69)$ \\
\hline \multicolumn{3}{|c|}{ Below-ground sucrose } \\
\hline P-preculture (P) & $1 / 116$ & $1.08(0.3)$ \\
\hline $\mathrm{N}$ supply $(\mathrm{N})$ & $1 / 116$ & $5.3(0.023)$ \\
\hline Light levels (L) & $1 / 116$ & $97.2(<\mathbf{0 . 0 0 0 1})$ \\
\hline $\mathrm{P} \times \mathrm{N}$ & $1 / 116$ & $2.73(0.1)$ \\
\hline $\mathrm{P} \times \mathrm{L}$ & $1 / 116$ & $12.2(\mathbf{0 . 0 0 0 6})$ \\
\hline $\mathrm{N} \times \mathrm{L}$ & $1 / 116$ & $0.02(0.885)$ \\
\hline \multicolumn{3}{|c|}{ Above-ground phosphorous } \\
\hline P-preculture (P) & $1 / 19$ & $8.99(\mathbf{0 . 0 0 7 3})$ \\
\hline $\mathrm{N}$ supply (N) & $1 / 19$ & $2.08(0.16)$ \\
\hline Light levels (L) & $1 / 19$ & $13.4(\mathbf{0 . 0 0 1 6})$ \\
\hline $\mathrm{P} \times \mathrm{N}$ & $1 / 19$ & $7.3(\mathbf{0 . 0 1 4})$ \\
\hline $\mathrm{P} \times \mathrm{L}$ & $1 / 19$ & $0.41(0.53)$ \\
\hline $\mathrm{N} \times \mathrm{L}$ & $1 / 19$ & $0.01(0.90)$ \\
\hline \multicolumn{3}{|c|}{ Above-ground phosphorous } \\
\hline P-preculture (P) & $1 / 19$ & $0.12(0.73)$ \\
\hline $\mathrm{N}$ supply (N) & $1 / 19$ & 13.1 (0.0018) \\
\hline Light levels (L) & $1 / 19$ & 23.1 (0.0001) \\
\hline $\mathrm{P} \times \mathrm{N}$ & $1 / 19$ & $1.49(0.24)$ \\
\hline $\mathrm{P} \times \mathrm{L}$ & $1 / 19$ & $0.30(0.59)$ \\
\hline $\mathrm{N} \times \mathrm{L}$ & $1 / 19$ & $8.01(0.33)$ \\
\hline \multicolumn{3}{|l|}{$F_{\mathrm{v}} / F_{\mathrm{m}}$} \\
\hline P-preculture (P) & $1 / 40$ & $0.509(0.48)$ \\
\hline N supply (N) & $1 / 40$ & $7.47(\mathbf{0 . 0 1 2})$ \\
\hline Light levels (L) & $1 / 40$ & $0.026(0.87)$ \\
\hline
\end{tabular}

and belowground tissues were significantly affected by light and ammonium, but not by the phosphate pretreatment (Table 1, Fig. 2A). A reduction of sucrose occurred mostly under light deprivation and was more acute under elevated ammonium supply (Fig. 2A).

The development of the sucrose content over the course of the experiment revealed that its mobilization and accumulation (considering the increase or decrease from initial levels) started immediately at the beginning of the experiment (Fig. 2B,C). Overall, at the end of the experiment (Day 21), EPUs grown at HL showed the highest levels of sucrose (compared to the content at Day 0), especially in belowground parts. Values were particularly high in EPUs from the HL $+\mathrm{N}$ 


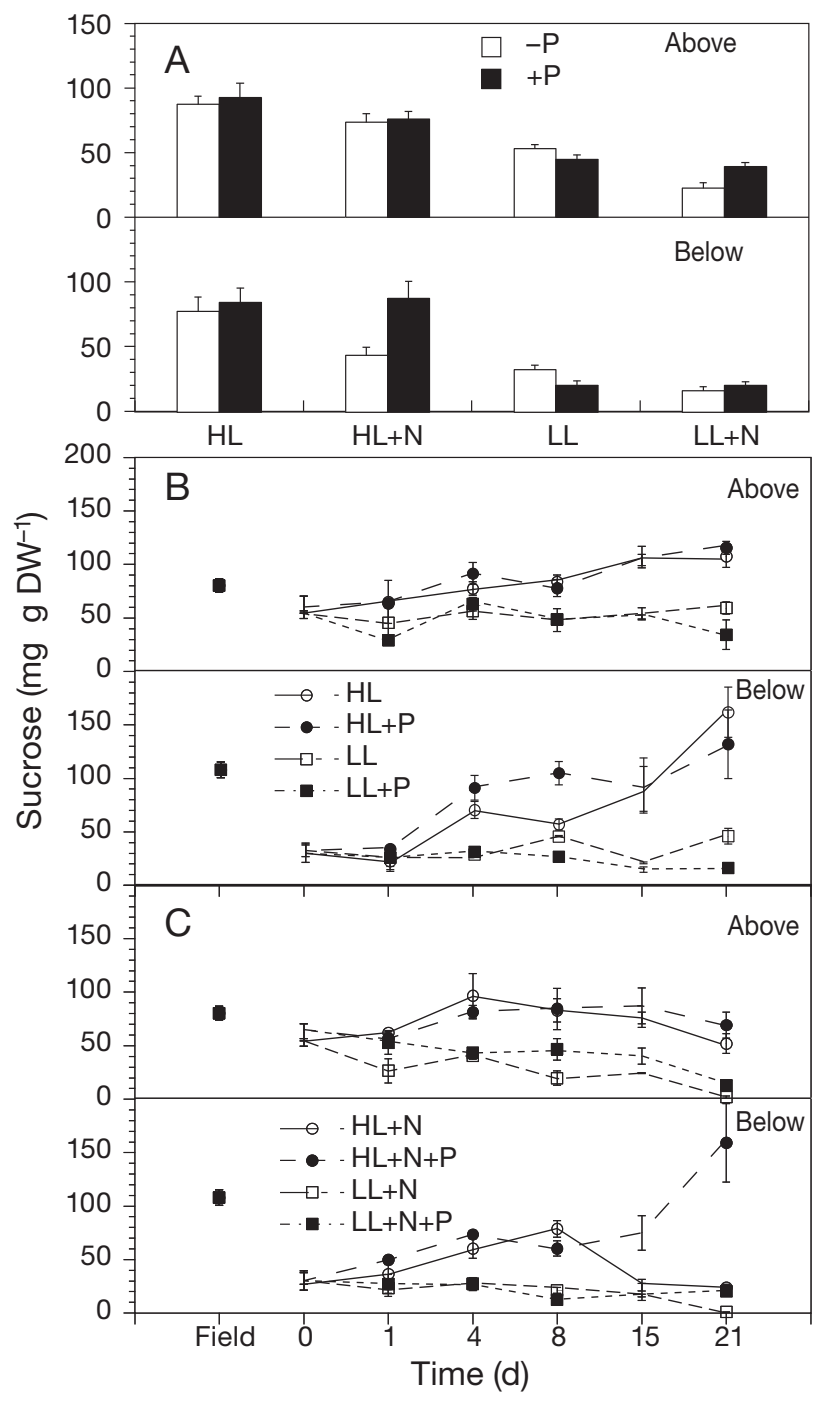

Fig. 2. Zostera noltii. Sucrose concentration in above- and belowground tissues in plants subjected to a factorial experimental design with light (HL: high light; LL: low light), phosphate precultivation $(+\mathrm{P})$ and ammonium supply $(+\mathrm{N})$ as factors. (A) Above- and belowground sucrose concentration for the entire experiment $(n=30)$. (B) Time course of above- and belowground sucrose concentration in plants subjected to light and P-precultivation treatments. (C) Time course of above- and belowground sucrose concentration in plants subjected to light, ammonium supply and P-precultivation treatments. Plants were harvested for analysis at times 1, 4, 815 and $21 \mathrm{~d}(\mathrm{n}=6)$. Time 0 denotes plants harvested once the Pprecultivation phase ended (the precultivation phase lasted $14 \mathrm{~d}$ ). Data for field plants (plants harvested for the experiment) are also included on the graphs. The experiment lasted for $21 \mathrm{~d}$. Data are presented as means $\pm 1 \mathrm{SE}$. DW: dry weight

+ P treatment (Fig. 2B,C); occasionally, the sucrose levels of these EPUs were even higher than those encountered in field plants. In contrast, EPUs grown at LL fostered a general mobilisation of sucrose, especially in the ammonium treatment, where concentrations were close to detection limits (Fig. 2C). Average starch con-

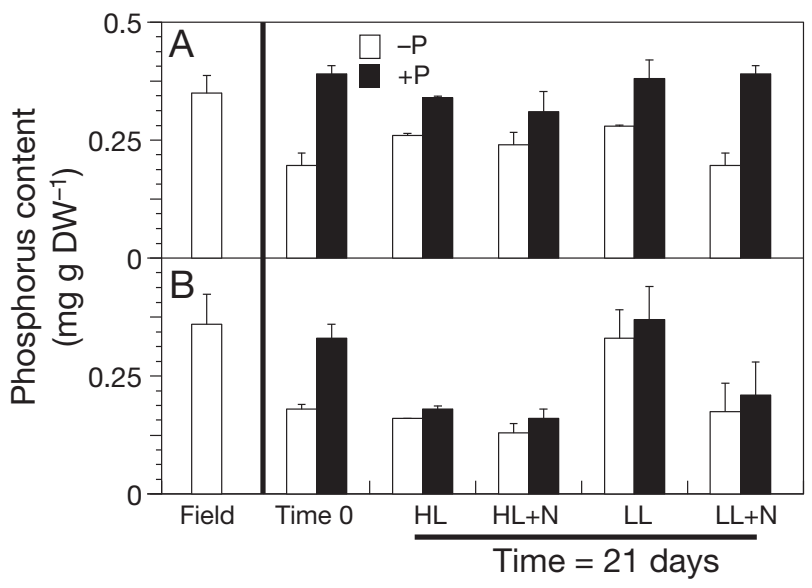

Fig. 3. Zostera noltii. Phosphorus content of (A) above- and (B) belowground tissues in plants subjected to a factorial experimental design with light (HL: high light; LL: low light), phosphate precultivation (+P: added phosphate, $-\mathrm{P}$ : no added phosphate) and ammonium supply $(+\mathrm{N})$ as factors, after $21 \mathrm{~d}$ of experiment. Time 0 denotes plants harvested once the phosphate precultivation phase ended (precultivation phase lasted $14 \mathrm{~d}$ ). Data for field plants (plants harvested for the experiment) are also included on the graphs. Data are presented as means + 1 SE $(n=6)$

tent in both above- and belowground parts accounted for a low proportion of the NSC $(<10 \%$; data not shown). Levels were significantly affected by light, but not by ammonium addition or phosphate over preculture conditions. Overall, smooth increases in starch were recorded over the experimental period, with slight net accumulations mostly in the aboveground parts of EPUs grown at HL (data not shown).

Tissue P levels of P-precultured plants were similar to values found in field plants and were, on average, 2 times higher than in P-starved plants (Fig. 3, Table 2). While the belowground $\mathrm{P}$ levels were significantly affected by light and ammonium supply, no significant effect was found for the aboveground contents.

\section{Fluorescence}

\section{Effects of precultivation phase}

Precultivation with phosphate slightly affected $F_{\mathrm{v}} / F_{\mathrm{m}}$ values. A significant decrease in phosphate-deficient plants was observed, in contrast to plants that precultured with added phosphate, which maintained similar values to the field (initial) plants (Table 3). Parameters of RLCs indicated that phosphate-enriched and initial plants generally performed better than phosphatedeficient plants, having the highest $\alpha, \mathrm{rETR}_{\mathrm{m}}$ and $I_{\text {opt }}$. However, only $I_{\text {opt }}$ was significantly higher in phosphate-enriched plants (Table 3 ). 
Table 3. Zostera noltii. Maximum quantum yield $\left(F_{\mathrm{v}} / F_{\mathrm{m}}\right)$ and the rapid light curve parameters $\alpha, \mathrm{rETR}_{\mathrm{m}}$ (all in relative units) and $I_{\text {opt }}\left(\mu \mathrm{mol}\right.$ photons $\mathrm{m}^{-2} \mathrm{~s}^{-1}$ ) of plants immediately after collection from the field (Initial) and after $1 \mathrm{wk}$ of incubation in a medium with $(+\mathrm{P})$ and without $(-\mathrm{P})$ added phosphate (values $\pm 1 \mathrm{SE}, \mathrm{n}=10)$. Letters next to values indicate significant differences $(\mathrm{p}<0.05)$ between treatments

\begin{tabular}{|lcccc|}
\hline Treatment & $F_{\mathrm{v}} / F_{\mathrm{m}}$ & $\alpha$ & $\mathrm{rETR}_{\mathrm{m}}$ & $I_{\mathrm{opt}}$ \\
\hline Initial & $0.79 \pm 0.01^{\mathrm{a}}$ & $0.34 \pm 0.02$ & $31.0 \pm 2.9$ & $231.4 \pm 31.8^{\mathbf{a}}$ \\
$+\mathrm{P}$ & $0.79 \pm 0.01^{\mathbf{a}}$ & $0.35 \pm 0.03$ & $31.9 \pm 2.0$ & $305.0 \pm 27.7^{\mathbf{a}}$ \\
$-\mathrm{P}$ & $0.76 \pm 0.01^{\mathbf{b}}$ & $0.31 \pm 0.02$ & $26.6 \pm 2.1$ & $155.2 \pm 17.2^{\mathbf{b}}$ \\
\hline
\end{tabular}

Effects of experimental treatments

Initial maximum photosynthetic efficiencies were relatively high $\left(F_{\mathrm{v}} / F_{\mathrm{m}}>0.75\right)$ and decreased slightly with time in all treatments. The most pronounced changes were observed in ammonium-enriched plants (reductions to $10 \%$ ), regardless of light levels or precultivation conditions (data not shown). The results of the ANOVA revealed a significant effect of time, ammonium supply and phosphate-precultivation on $F_{\mathrm{v}} / F_{\mathrm{m}}$ (Table 1). At the end of the experiment (Day 21), only ammonium as a single stressor significantly affected the $F_{\mathrm{v}} / F_{\mathrm{m}}$ values (Table 2). No clear patterns could be detected in the parameters obtained from the RLCs, due to the high variability at all levels and for all parameters (data not shown).

\section{DISCUSSION}

The present study showed that light deprivation, ammonium supply and phosphate precultivation significantly affected the net production, NSC pool and fluorescence parameters of Zostera noltii. It also revealed that the harmful effects of low light and ammonium enrichment (either separately or simultaneously) on net production could be alleviated by preculturing plants added with phosphate. This has to our knowledge, not previously been reported in seagrasses.

Precultivation with added phosphate resulted in 3 different effects: (1) ammonium toxicity was largely ameliorated, (2) weight losses under LL were reduced and (3) net production under HL was increased. The latter response would probably indicate that plants precultured without added phosphate suffered from phosphate limitation. In fact, average phosphorus content in tissues of these plants $(0.19 \%$ dry weight, DW), was lower than that in plants precultured with added phosphate $(0.31 \% \mathrm{DW})$ and field plants at the sampling site (0.6\% DW; Brun et al. 2003a), and close to the lower limit for a large number of seagrass spe- cies (0.2\%; Duarte 1990), supporting the hypothesis of phosphate limitation.

As previously reported by van Katwijk et al. (1997) and Brun et al. (2002), we found that ammonium in seawater was toxic at concentrations 10 to 20 times lower than those usually found in Zostera noltii meadows growing near wastewater and run-off discharge points with concentrations up to 200 to $663 \mu \mathrm{m} \mathrm{NH}_{4}{ }^{+}$/DIN (Hernández et al. 1997, Cabaço 2007, Cabaço et al. 2007). Similarly high phosphate concentrations were also found in such waters (up to $54 \mu \mathrm{m}$ in Cabaço 2007). The positive effect of phosphate addition under severe ammonium toxicity when both nutrients were simultaneously supplied was previously reported for this species (Brun et al. 2002). In contrast, in the present study, plants (50\% of the total EPUs) were precultivated with added phosphate, and only ammonium was added during the experimental phase. Therefore, the phosphate stored during the precultivation phase and its further mobilization could account for these positive effects. This result highlights the importance of 'phosphorus luxury consumption', that is, the uptake of nutrients in excess of the plant's requirements and its storage for a posterior use when external supply decreases (Invers et al. 2002). Phosphorous is assimilated in organic matter in a rather constant stoichiometric ratio with nitrogen (Duarte 1990). $P$ limitation would imbalance the average N/P ratio, and it has been suggested to be one of the causes of nitrogen (both ammonium and nitrate) toxicity in seagrasses (Burkholder et al. 1992, 1994, Brun et al. 2002). Moreover, since ammonium uptake is accompanied by an increase in intracellular inorganic anions to balance the intracellular potential (e.g. phosphate; Cruz et al. 1993, van Katwijk et al. 1997), it would confer some advantages to plants precultured with added phosphate, as they possess a larger phosphorus quota.

Ammonium assimilation generates a strong depletion of carbon skeletons. These carbon reserves are provided by photosynthesis and/or by the mobilization of the NSC pool. Light treatments resulted in significant differences in the NSC pool. Under LL, there was an initial reduction in sucrose synthesis, with a subsequent use of sucrose and starch resulting in critically low sucrose concentrations. Similar findings were reported for Zostera noltii (Peralta et al. 2002, Brun et al. 2003b,c, Olivé et al. 2007) and other seagrass species (Burke et al. 1996, Ruíz \& Romero 2001). The almost complete depletion of the sucrose pool in LL $+\mathrm{N}$ plants highlights the importance of carbon reserves to counterbalance ammonium toxicity. 
The harmful effect of ammonium enrichment (e.g. reduction in net production) was more apparent in HL than in LL-grown plants, while the strongest effect was recorded between phosphate added and no phosphate added preculture treatments. Moreover, the drop in net production seemed to be unrelated to carbon reserves, since similar NSC concentrations were recorded between HL treatments (including phosphatepreculture and ammonium supply treatments). Comparable results were found in land plants (Goyal et al. 1982, Bendixen et al. 2001). At a first glance, this result would not agree with the hypothesis that the increased demand for skeletal carbon caused by ammonium assimilation could be counterbalanced by the increased photosynthetic carbon supply fostered by a higher light availability. However, Britto et al. (2001, p. 4258) argued that 'the inability of barley and other species with high susceptibility to ammonium toxicity, to exclude $\mathrm{NH}_{4}{ }^{+}$by regulation of plasma-membrane influx systems constitutes a fundamental breakdown in plant cell function (increment in more than $47 \%$ of the energetic costs) and must precede any intracellular toxicity-associated events such as cation displacement or carbohydrate depletion', which is consistent with our findings. This topic deserves future research effort in seagrasses, since, in contrast to land plants, they: (1) can take up nutrients through leaves as well as roots, (2) lack any ammonium uptake feedback mechanism and (3) seem to be more vulnerable to ammonium toxicity than land plants. Furthermore, studies dealing with nitrogen toxicity have focused mainly on 2 seagrass species (Zostera noltii and Z . marina). Thus, such studies must be extended to other seagrass species to gain a better and more general knowledge of the underlying physiological mechanisms of nitrogen toxicity and the consequences for individual species and seagrass-dominated ecosystems.

Our results may have important ecological and management implications. P-limitation in seagrasses has been shown experimentally, especially in plants growing on carbonate sediments (Short et al. 1990, Perez et al. 1991, Duarte \& Sand-Jensen 1996). The present study showed that P-limitation resulted in the reduced capacity of Zostera noltii to respond to unfavourable light and/or ammonium conditions, making this species more vulnerable under these environmental conditions. Therefore, deeper insight into the relationship between nutrient limitation and seagrass vulnerability will improve our knowledge on seagrass decline and our management capacity of seagrass-dominated ecosystems.

Acknowledgements. F.G.B. is supported by an individual Marie Curie fellowship (MEIF-CT-2005-515071) and by a European Reintegration Grant (MERG-CT-2007-205675). I.O. holds an FPU grant from the Ministerio de Educación y Ciencia. This work was also funded by the Spanish Project
CTM2005-00395/MAR. The authors are grateful to 3 anonymous reviewers and the editor for their valuable comments on the manuscript. This is NIOO Publication Number 4283. This article is dedicated to my second son, Alvaro Brun Selma, who was born in January 2008 (F.G.B.).

\section{LITERATURE CITED}

APHA (American Public Health Association) (1992) Standard methods for the examination of water and wastewater, 18th edn. American Public Health Association, Washington, DC

Bendixen R, Gerendás J, Schinner K, Sattelmacher B, Hansen UP (2001) Difference in zeaxanthin formation in nitrateand ammonium grown Phaseolus vulgaris. Physiol Plant 111:255-261

Bischof K, Hanelt D, Wiencke C (2000) Effects of ultraviolet radiation on photosynthesis and related enzyme reactions of marine macroalgae. Planta 211:555-562

Britto DT, Kronzucher HJ (2002) $\mathrm{NH}_{4}{ }^{+}$toxicity in higher plants: a critical review. J Plant Physiol 159:567-584

Britto DT, Siddiqui MY, Glass ADM, Kronzucher HJ (2001) Futile transmembrane $\mathrm{NH}_{4}{ }^{+}$cycling: a cellular hypothesis to explain ammonium toxicity in plants. Proc Natl Acad Sci USA 98:4255-4258

Brun FG, Vergara JJ, Hernández I, Peralta G, Pérez-Lloréns JL (2002) Assessing the toxicity of ammonium pulses in the survival and growth of Zostera noltii Hornem. Mar Ecol Prog Ser 225:177-187

Brun FG, Pérez-Lloréns JL, Vergara JJ, Hernández I (2003a) Patch distribution and within-patch dynamics of the seagrass Zostera noltii Hornem at Los Toruños salt-marsh (Cádiz Bay, Natural Park, Spain). Bot Mar 46:513-524

Brun FG, Vergara JJ, Hernández I, Pérez-Lloréns JL (2003b) Growth, carbon allocation and proteolytic activity in the seagrass Zostera noltii shaded by Ulva canopies. Funct Plant Biol 30:551-560

Brun FG, Vergara JJ, Navarro G, Hernández I, Pérez-Lloréns JL (2003c) Effect of shading by Ulva rigida canopies on growth and carbon balance of the seagrass Zostera noltii. Mar Ecol Prog Ser 265:85-96

Burke MK, Denninson WC, Moore KA (1996) Non-structural carbohydrate reserves of eelgrass Zostera marina. Mar Ecol Prog Ser 137:195-201

> Burkholder JM, Mason KM, Glasgow HB (1992) Water-column nitrate enrichment promotes decline of eelgrass Zostera marina: evidence from seasonal mesocosm experiments. Mar Ecol Prog Ser 81:163-178

Burkholder JM, Glasgow HB Jr, Cooke JE (1994) Comparative effects of water-column nitrate enrichment on eelgrass Zostera marina, shoalgrass Halodule wrightii, and widgeongerass Ruppia maritima. Mar Ecol Prog Ser 105: 121-138

Cabaço S (2007) Impact of anthropogenic activities on the seagrass Zostera noltii. PhD thesis, University of Algarve, Faro

Cabaço S, Machas R, Santos R (2007) Biomass-density relationships of the seagrass Zostera noltii: a tool for monitoring anthropogenic nutrient disturbance. Estuar Coast Shelf Sci 74:557-564

Cruz C, Lips SH, Martinsloucao MA (1993) Growth and nutrition of carob plants as affected by nitrogen sources. J Plant Nutr 16:1-15

> Duarte CM (1990) Seagrass nutrient content. Mar Ecol Prog Ser 67:201-207

- Duarte CM, Sand-Jensen K (1996) Nutrient constraints on establishment from seed and on vegetative expansion of 
the Mediterranean seagrass Cymodocea nodosa. Aquat Bot 54:279-286

Goyal SS, Lorenz OA, Huffaker RC (1982) Inhibitory effects of ammoniacal nitrogen on the growth of radish plants. I. Characterization of toxic effects of $\mathrm{NH}_{4}{ }^{+}$on growth and its alleviation by $\mathrm{NO}_{3}{ }^{-}$. J Am Soc Hortic Sci 107:125-129

Hernández I, Peralta G, Pérez-Lloréns JL, Vergara JJ, Niell FX (1997) Biomass and dynamics of growth of Ulva species in Palmones River Estuary. J Phycol 33:764-772

Huber SC, Israel DW (1982) Biochemical basis for partitioning of photosynthetically fixed carbon between starch and sucrose in soybean (Glycine max Merr.) leaves. Plant Physiol 69:691-696

Iizumi H, Hattori A (1982) Growth and organic production of eelgrass (Zostera marina L.) in temperate waters of the Pacific coast of Japan. III. The kinetics of nitrogen uptake. Aquat Bot 12:245-256

Invers O, Pérez M, Romero R (2002) Seasonal speciation in temperate seagrass Posidonia oceanica (L.) Delile. J Exp Mar Biol Ecol 273:219-240

Invers O, Kraemer GP, Pérez M, Romero J (2004) Effects of nitrogen addition on nitrogen metabolism and carbon reserves in the temperate seagrass Posidonia oceanica. J Exp Mar Biol Ecol 303:97-114

Kirkby EA (1968) Influence of ammonium and nitrate nutrition on the cation-anion balance and nitrogen and carbohydrate metabolism of white mustard plants grown in dilute nutrient solutions. Soil Sci 105:133-141

Koroleff F (1976) Determination of ammonia. In: Grasshoff K (ed) Methods of seawater analysis. Verlag Chemie, New York, p 126-133

Krause GH, Weis E (1991) Chlorophyll fluorescence and photosynthesis-the basics. Annu Rev Plant Physiol Plant Mol Biol 42:313-349

Longstaff BJ, Loneragan NR, O'Donohue MJ, Dennison WC (1999) Effects of light deprivation on the survival and recovery of the seagrass Halophila ovalis (R.Br.) Hook. J Exp Mar Biol Ecol 234:1-27

Marschner H (1995) Mineral nutrition of higher plants, 2nd edn. Academic Press, New York

Murphy J, Riley JP (1962) A modified single solution method for the determination of phosphate in natural waters. Anal Chim Acta 27:31-36

Editorial responsibility: Matthias Seaman, Oldendorf/Luhe, Germany
Olivé I, Brun FG, Vergara JJ, Pérez-Lloréns JL (2007) Effects of light and biomass partitioning on growth, photosynthesis and carbohydrate content of the seagrass Zostera noltii Hornem. J Exp Mar Biol Ecol 345:90-100

> Peralta G, Pérez-Lloréns JL, Hernández I, Vergara JJ (2002) Effects of light availability on growth, architecture and nutrient content of the seagrass Zostera noltii Hornem. J Exp Mar Biol Ecol 269:9-26

> Perez M, Romero J, Duarte CM, Sand-Jensen K (1991) Phosphorous limitation of Cymodocea nodosa growth. Mar Biol 109:129-133

Platt T, Gallegos CL, Harrison WG (1980) Photoinhibition of photosynthesis in natural assemblages of marine phytoplankton. J Mar Res 38:687-701

Ralph PJ, Tomasko D, Moore KA, Seddon S, McGinnis-Ng CMO (2006) Human impact on seagrass: eutrophication, sedimentation and contamination In: Larkum AWD, Orth R, Duarte CM (eds) Seagrasses: biology, ecology and conservation. Springer, Heidelberg, p 567-593

> Ruíz JM, Romero J (2001) Effects of in situ experimental shading on the Mediterranean seagrass Posidonia oceanica. Mar Ecol Prog Ser 215:107-120

Short FT, Wyllie-Echevarria S (1996) Natural and humaninduced disturbance of seagrasses. Environ Conserv 23: $17-27$

Short FT, Dennison W, Capone DG (1990) Phosphorous-limited growth of the tropical seagrass Syringodium filiforme in carbonate sediments. Mar Ecol Prog Ser 62:169-174

Thursby GB, Harlin MM (1982) Leaf-root interaction in the uptake of ammonia by Zostera marina. Mar Biol 72:109-112

Touchette BW, Burkholder JM (2000) Overview of the physiological ecology of carbon metabolism in seagrass. J Exp Mar Biol Ecol 250:169-205

Valiela I, McClelland J, Hauxwell J, Behr PJ, Hersh D, Foreman K (1997) Macroalgal blooms in shallow estuaries: controls and ecophysiological and ecosystem consequences. Limnol Oceanogr 42:1105-1118

van Katwijk MM, Vergeer LHT, Schmitz GHW, Roelofs JGM (1997) Ammonium toxicity in eelgrass Zostera marina. Mar Ecol Prog Ser 157:159-173

Zar JH (1984) Biostatistical analysis, 2nd edn. Prentice Hall, Englewood Cliffs, New Jersey

Submitted: July 10, 2007; Accepted: April 7, 2008

Proofs received from author(s): July 25, 2008 